\title{
Clinical utility gene card for: DiGeorge syndrome, velocardiofacial syndrome, Shprintzen syndrome, chromosome 22q11.2 deletion syndrome (22q11.2, TBX1)
}

Eberhard Schwinger ${ }^{\star}, 1$ Koen Devriendt ${ }^{2}$, Anita Rauch ${ }^{3}$ and Nicole Philip ${ }^{4}$

European Journal of Human Genetics (2010) 18, doi:10.1038/ejhg.2010.5; published online 3 February 2010

\section{DISEASE CHARACTERISTICS}

1.1 Name of the disease (synonyms)

DiGeorge syndrome (DGS), velocardiofacial syndrome (VCFS), Shprintzen syndrome, Takao syndrome, Sedlackova syndrome, chromosome 22q11.2 deletion syndrome.

\subsection{OMIM\# of the disease}

188400 (DGS), 192430 (VCFS).

1.3 Name of the analysed genes or DNA/chromosome segments 22q11.2, TBX1.

\subsection{OMIM\# of the gene(s)}

602054 (TBX1).

\subsection{Mutational spectrum}

Deletions in 22q11.2:1,2

$3 \mathrm{Mb}(90 \%$ of cases $)$

$1.5 \mathrm{Mb}(7-8 \%$ of cases)

Atypical smaller deletions.

Point mutations in TBX1. ${ }^{3}$

\subsection{Analytical methods}

FISH, MLPA, quantitative PCR, array CGH, sequencing.

Conventional cytogenetics usually normal except for rare cases resulting from unbalanced translocations.

\subsection{Analytical validation}

Parallel analysis of positive and negative controls, depending on the method.

\subsection{Estimated frequency of the disease}

(incidence at birth ('birth prevalence') or population prevalence) Prevalence at birth: 1:5000 (ranges from 1:4000 to 1:10000 in the literature).$^{4-8}$

1.9 If applicable, prevalence in the ethnic group of investigated person

None.

\subsection{Diagnostic setting}

\begin{tabular}{lcc}
\hline & Yes & No \\
\hline A. (Differential) diagnostics & $\Downarrow$ & $\square$ \\
B. Predictive testing & $\square$ & $\square$ \\
C. Risk assessment in relatives & $\Downarrow$ & $\square$ \\
D. Prenatal & $\Downarrow$ & $\square$ \\
\hline
\end{tabular}

\section{TEST CHARACTERISTICS}

\begin{tabular}{|c|c|c|c|c|}
\hline & \multicolumn{2}{|c|}{ Genotype or disease } & \multirow{2}{*}{$\begin{array}{l}\text { A: True positives } \\
\text { B: False positives }\end{array}$} & \multirow{2}{*}{$\begin{array}{l}\text { C: False negative } \\
\text { D: True negative }\end{array}$} \\
\hline & Present & Absent & & \\
\hline \multicolumn{5}{|l|}{ Test } \\
\hline Positive & $A$ & B & $\begin{array}{l}\text { Sensitivity: } \\
\text { Specificity: }\end{array}$ & $\begin{array}{l}A /(A+C) \\
D /(D+B)\end{array}$ \\
\hline Negative & C & D & $\begin{array}{l}\text { Positive predictive value: } \\
\text { Negative predictive value: }\end{array}$ & $\begin{array}{l}A /(A+B) \\
D /(C+D)\end{array}$ \\
\hline
\end{tabular}

\subsection{Analytical sensitivity}

(proportion of positive tests if the genotype is present)

Depends on analytical method:

Typical 3 and $1.5 \mathrm{Mb}$ deletions: almost $100 \%$ for all methods.

Atypical deletions: FISH: $>95 \%$.

MLPA, array CGH: virtually $100 \%$.

Point mutations in TBX1: $\%$, requires sequencing (research). ${ }^{9,10}$

\subsection{Analytical specificity}

(proportion of negative tests if the genotype is not present)

Nearly $100 \%$.

\footnotetext{
${ }^{1}$ Institute of Human Genetics, University Hospital Schleswig-Holstein, Lübeck, Germany; ${ }^{2}$ Centre for Human Genetics, University Hospital Gasthuisberg, Leuven, Belgium; ${ }^{3}$ Institute of Human Genetics, University of Erlangen-Nürnberg, Erlangen, Germany; ${ }^{4}$ Département de Génétique Médicale, Hôpital d'Enfants de la Timone, Marseille, France *Correspondence: Professor E Schwinger, Institute of Human Genetics, Universitätsklinikum Schleswig-Holstein Allee 160, D-23538 Lübeck, Germany. Tel: +49 4515006055 ; Fax: +49 451500 4187; E-mail: schwing@uni-luebeck.de
} 
2.3 Clinical sensitivity

(proportion of positive tests if the disease is present)

In such cases a general statement should be given, even if a quantification can only be carried out case by case.

95\%. The DGS phenotype in a neonate can be mimicked by certain other chromosomal imbalances (eg, a deletion in 10p13-p14), monogenic conditions (eg, CHARGE syndrome) or disorders caused by teratogens (eg, retinoid or maternal diabetes).

\subsection{Clinical specificity}

(proportion of negative tests if the disease is not present)

The clinical specificity can be dependent on variable factors such as age or family history. In such cases a general statement should be given, even if a quantification can only be carried out case by case.

Depends on the quality of clinical assessment due to highly variable expressivity of the disease.

As most apparently healthy carriers show at least minimal manifestations of the disease on careful examination, the clinical specificity is nearly $100 \%$.

In familial cases, mosaics can be found in 'healthy' truly asymptomatic persons.

2.5 Positive clinical predictive value

(lifetime risk to develop the disease if the test is positive)

$100 \%$, but high clinical variability.

\subsection{Negative clinical predictive value}

(probability not to develop the disease if the test is negative)

Assume an increased risk based on family history for a nonaffected person. Allelic and locus heterogeneity may need to be considered.

Index case in that family had been tested:

Practically $100 \%$.

Index case in that family had not been tested:

Can only be clarified through analysis of the non-affected person.

\section{CLINICAL UTILITY}

3.1 (Differential) diagnosis: the tested person is clinically affected (To be answered if in 1.10 'A' was marked)

\subsubsection{Can a diagnosis be made other than through a genetic test?}

\begin{tabular}{ll}
\hline No & $\otimes$ (continue with 3.1.4) \\
Yes & $\square$ \\
& Clinically \\
& Imaging \\
& Endoscopy \\
& Biochemistry \\
& Electrophysiology \\
& Other (please describe)
\end{tabular}

3.1.2 Describe the burden of alternative diagnostic methods to the patient

Not applicable.

3.1.3 How is the cost effectiveness of alternative diagnostic methods to be judged?

Not applicable.
3.1.4 Will disease management be influenced by the result of a genetic test?

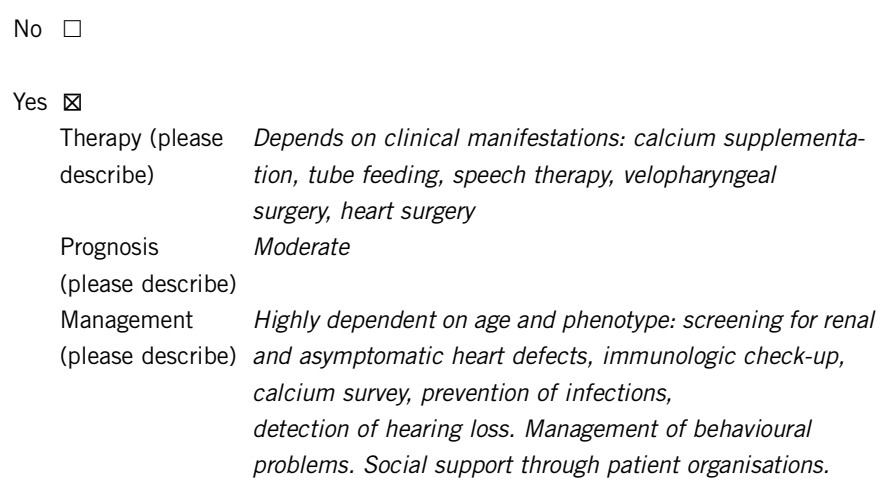

3.2 Predictive setting: the tested person is clinically unaffected but carries an increased risk based on family history

(To be answered if in 1.10 'B' was marked)

3.2.1 Will the result of a genetic test influence lifestyle and prevention?

Yes.

If the test result is positive (please describe):

Yes, see 3.1.4.

If the test result is negative (please describe):

Depends on clinical manifestations.

3.2.2 Which option in view of lifestyle and prevention does a person at risk have if no genetic test has been done (please describe)? No special options.

3.3 Genetic risk assessment in family members of a diseased person (To be answered if in 1.10 'C' was marked)

3.3.1 Does the result of a genetic test resolve the genetic situation in that family?

Yes, but only when the relatives are tested too.

3.3.2 Can a genetic test in the index patient save genetic or other tests in family members?

Yes.

3.3.3 Does a positive genetic test result in the index patient enable a predictive test in a family member?

Unaffected or only minimally affected relatives can be diagnosed by the test and may then profit from preventive measures (eg, calcium). If a deletion is detected in a parent, prenatal diagnosis is possible for further pregnancies.

\subsection{Prenatal diagnosis}

(To be answered if in 1.10 'D' was marked)

3.4.1 Does a positive genetic test result in the index patient enable a prenatal diagnostic?

Yes.

\section{IF APPLICABLE, FURTHER CONSEQUENCES OF TESTING}

Please assume that the result of a genetic test has no immediate medical consequences. Is there any evidence that a genetic test is nevertheless useful for the patient or his/her relatives? (Please describe) Parents are given accurate information about the cause of the disease and recurrence risk. 


\section{CONFLICT OF INTEREST}

The authors declare no conflict of interest.

\section{ACKNOWLEDGEMENTS}

This work was supported by EuroGentest, an EU-FP6 supported NoE, contract number 512148 (EuroGentest Unit 3: 'Clinical genetics, community genetics and public health', Workpackage 3.2).

1 Carlson C, Sirotkin H, Pandita R et al: Molecular definition of 22q11 deletions in 151 velo-cardio-facial syndrome patients. Am J Hum Genet 1997; 61: 620-629.

2 Emanuel B: Molecular mechanisms and diagnosis of chromosome 22q11.2 rearrangements. Dev Disabil 2008; 14: 11-18.
3 Yagi $\mathrm{H}$, Furutani Y, Hamada $\mathrm{H}$ et al: Role of $T B X 1$ in human del22q11.2 syndrome. Lancet 2003; 362: 1366-1373.

4 Tézenas Du Montcel S, Mendizabai H, Aymé S, Lévy A, Philip N: Prevalence of 22q11 microdeletion. J Med Genet 1996; 33: 719.

5 Goodship J, Cross I, LiLing J, Wren C: A population study of chromosome 22q11 deletions in infancy. Arch Dis Child 1998; 79: 348-51.

6 Oskarsdóttir S, Vujic M, Fasth A: Incidence and prevalence of the 22q11 deletion syndrome: a population-based study in western Sweden. Arch Dis Child 2004; 89: $148-151$.

7 Devriendt K, Fryns JP, Mortier G, van Thienen MN, Keymolen K: The annual incidence of DiGeorge/velocardiofacial syndrome. J Med Genet 1998; 35: 789-790.

8 Tan KB, Chew SK, Yeo GS: 22q11.2 deletion syndrome in Singapore (2000-2003): a case for active ascertainment. Singapore Med J 2008; 49: 286-289.

9 Emanuel B: Molecular mechanisms and diagnosis of chromosome 22q11.2 rearrangements. Dev Disabil 2008; 14: 11-18.

10 Vorstman JAS, Jalali GR, Rappaport EF, Hacker AM, Scott C, Emanuel BS: MLPA: a rapid, reliable and sensitive method for detection and analysis of abnormalities of $22 Q$. Hum Mutat 2006; 27: 814-821. 